NOVELTY will primarily be documented in electronic case report forms, not EMRs. The lack of lung function data in many countries suggested divergences in diagnosis of asthma/COPD between clinical guidelines (which include lung function tests) and clinical practice.

\begin{tabular}{|c|c|c|c|c|c|c|}
\hline Country & $\begin{array}{l}\text { EMR } \\
\text { source }\end{array}$ & $\begin{array}{l}\text { Age/ } \\
\text { sex, \% }\end{array}$ & $\begin{array}{l}\text { Height/ } \\
\text { weight, \% }\end{array}$ & $\begin{array}{l}\text { Lung function } \\
\text { tests, \% }\end{array}$ & $\begin{array}{l}\text { Haemat-ology } \\
\text { tests, \% }\end{array}$ & $\begin{array}{l}\text { PROs, } \\
\%\end{array}$ \\
\hline Australia & A (GPs) & 100 & $21-32$ & 0 & $31-66$ & 0 \\
\hline Canada & A & 100 & $34-42$ & $1-10$ & $38-52$ & 0 \\
\hline China & $\begin{array}{l}\text { B } \\
\text { (outpatient) }\end{array}$ & 100 & 0 & 0 & $2-83$ & 0 \\
\hline France & A & 99-100 & $13-46$ & 0 & 7-19 & 0 \\
\hline Germany & A & 100 & $18-23$ & 0 & 0 & 0 \\
\hline Italy & A & 79-100 & $18-24$ & $0-4$ & $13-23$ & 0 \\
\hline Japan & B & 100 & 0 & 0 & 0 & 0 \\
\hline Spain & A & 100 & $24-41$ & 0 & $26-35$ & 0 \\
\hline Sweden & c & 100 & $34-55$ & $33-56$ & NA & 0 \\
\hline UK & A (GPS) & 100 & $30-72$ & $0-57$ & $31-59$ & 0 \\
\hline USA & A, C & 100 & $32-100$ & $0-17$ & $10->70$ & 0 \\
\hline
\end{tabular}

A, physician records; B, hospital records; C, registries; COPD, chronic obstructive pulmonary disease; EMR, electronic medical record; GP, general practitioner; NA, available but not assessed; PROs, patient-reported outcomes.

Please refer to page A271 for declarations of interest in relation to abstract P138.

\section{P139 THE BURDEN OF COPD ACROSS THE EUROPEAN UNION: DEVELOPMENT OF THE EUROPEAN COPD ATLAS}

${ }^{1} \mathrm{JFM}$ van Boven, ${ }^{1} \mathrm{~J}$ Gaughan, ${ }^{2} \mathrm{JB}$ Soriano, ${ }^{3} \mathrm{~J}$ Correia de Sousa, ${ }^{4} \mathrm{~N}$ Baxter, ${ }^{5} \mathrm{M}$ RománRodríguez, ${ }^{6} \mathrm{~J}$ Vilaró, ${ }^{7} \mathrm{~S}$ Williams, ${ }^{8} \mathrm{~S}$ Fitch, ${ }^{9} \mathrm{~K}$ Kishore, ${ }^{9} \mathrm{H}$ Chaudhury. ${ }^{1}$ European COPD Coalition, Brussels, Belgium; ${ }^{2}$ Instituto de Investigación Hospital Universitario de la Princesa (IISP), Universidad Autónoma de Madrid, Madrid, Spain; ' ${ }^{3}$ Life and Health Sciences Research Institute (ICVS), School of Health Sciences, University of Minho, Braga, Portugal, ICVS/3B's PT Government Associate Laboratory, Braga/Guimarães, Portugal; ${ }^{4}$ NHS Southwark Clinical Commissioning Group, London, UK; ${ }^{5}$ Instituto de Investigación Sanitaria de las Islas Baleres (IdISPa) Balearic Health Service, Palma de Mallorca, Spain; ${ }^{6}$ Department of Physiotherapy, Ramon Llull University, Barcelona, Spain; 'IInternational Primary Care Respiratory Group, Westhill, UK; ${ }^{8}$ Fundación Lovexair, Madrid, Spain; ${ }^{9}$ Health IQ, London, UK

\subsection{6/thoraxjnl-2016-209333.282}

Background Estimating current and future impact of chronic obstructive pulmonary disease (COPD) within the European Union (EU) is essential for targeted and well-informed policymaking, however, current global and regional estimates are contradictory, and comparable standardised data is lacking. Without it the burden felt by individuals and healthcare systems cannot be fully quantified and a collective and coordinated response cannot be achieved to protect economies and communities from further harm.

Aim Our purpose was to

- Collect data to enable a comparative assessment of the COPD burden across EU 28 member states and highlight variation.

- Show the impact of COPD in the workplace, on healthcare utilisation and on quality of life of the EU population.

- Use the data to underpin a simulation model to demonstrate future impact on societies, health inequalities and healthcare utilisation depending on which interventions are selected.
Methods A systematic literature review was performed to identify regional and national data on COPD prevalence, risk factors (e.g. smoking, air pollution), impact and costs across the EU. Workshops with stakeholders from a range of European countries were convened to test the face validity of the data, and to develop policy-level questions from which a simulation model could be developed.

Results Prevalence estimates of COPD varied considerably $(1.26 \%$ to $13.87 \%)$, partly because of different definitions. As smoking rates are less affected by definition differences, these were used in a model that predicts COPD incidence, prevalence and mortality. Correction factors were applied to account for non-smoking related causes and under diagnosis of smoking. Smoking prevalence rates were used to estimate data for equivalent countries for the countries where smoking data were not available. The simulation model is currently in development and first results are expected in Autumn 2016.

Conclusion The European COPD Coalition (ECC) will use the results to facilitate dialogue with EU decision makers (European Commission Council and Parliament) on health policy, outlining the problem and providing evidence to support the call for political actions on COPD. It will also be of significant interest to healthcare professionals, patients, and respiratory organisations with a passion to improve COPD care

\section{P140 COMORBIDITIES OF SWEDISH PATIENTS DIAGNOSED WITH CHRONIC OBSTRUCTIVE PULMONARY DISEASE (COPD) AND/OR ASTHMA}

${ }^{1} \mathrm{G}$ Johansson, ${ }^{1} \mathrm{C}$ Jansen, ${ }^{2} \mathrm{M}$ Van Der Tol, ${ }^{3} \mathrm{R}$ Ariely, ${ }^{4} \mathrm{G}$ Bergman, ${ }^{4} \mathrm{M}$ Unde, ${ }^{4} \mathrm{P}$ Sobocki, ${ }^{2} \mathrm{H}$ Benhaddi. ' Uppsala University, Uppsala, Sweden; ${ }^{2}$ Teva Pharmaceuticals (Amsterdam), Amsterdam, The Netherlands; ${ }^{3}$ Teva Pharmaceuticals (Frazer), Frazer, USA; ${ }^{4}$ MS Health, Solma, Sweden

10.1136/thoraxjnl-2016-209333.283

Introduction and objectives Standard of care treatments for asthma and COPD are commonly administered in single-dose or multidose dry powder inhalers. There is a dearth of evidence around the prevalence of comorbidities, especially those that may affect inhaler device handling, among Swedish asthma and COPD patients.

Methods This retrospective study from the Swedish National Health Registries included 495,254 patients receiving inpatient or specialised outpatient care in Sweden between January 1, 2005 and December 31, 2014. Estimates of severity were based on number of asthma/COPD drugs used. Diagnostic codes were used to assess number of patients with a pre-specified comorbidity potentially affecting device handling.

Results Patient characteristics, treatments and comorbidities are summarised in the Table. Comorbidities that may impact inhaler handling were observed in 15.8\% (asthma), 50.4\% (COPD) and $55.3 \%$ (asthma/COPD) patients; incidence was increased with disease severity (patients with severe disease: 26.3\%, 52.0\%, $55.9 \%$ ) and advanced age (patients 60-69 years: $33.2 \%, 45.2 \%$, $50.5 \%$, respectively).

Conclusions Comorbidities potentially affecting device handling were common across all groups, and unexpectedly high among elderly asthma patients. Furthermore, the data indicate that a substantial percentage of patients use two or more separate inhalers. These findings highlight the need for newer, easier to use inhalers, as well as training and monitoring of device use in patients who may have more difficulties using their devices correctly due to comorbidities. 
Abstract P140 Table 1

\begin{tabular}{|c|c|c|c|}
\hline & $\begin{array}{l}\text { Asthma } \\
(\mathrm{n}=394,160)\end{array}$ & $\begin{array}{l}\text { COPD } \\
(n=77,749)\end{array}$ & $\begin{array}{l}\text { Asthma and } \\
\text { COPD } \\
(\mathrm{n}=23,345)\end{array}$ \\
\hline Mean age, year (SD) & $28.9(24.7)$ & $72.8(9.8)$ & $71.7(10.9)$ \\
\hline Male & $50.6 \%$ & $47.5 \%$ & $38.5 \%$ \\
\hline \multicolumn{4}{|l|}{ Severity } \\
\hline Mild/moderate/severe/very severe & $\begin{array}{l}61.4 \% / 34.9 \% / \\
3.6 \% / 0 \%\end{array}$ & $\begin{array}{l}42.8 \% / \\
38.8 \% / \\
16.0 \% / 2.4 \%\end{array}$ & $\begin{array}{l}23.0 \% / 44.3 \% / \\
27.7 \% / 5.0 \%\end{array}$ \\
\hline Mean Charlson Comorbidity index (SD) & $1.3(1.1)$ & $3.0(2.2)$ & $2.9(2.2)$ \\
\hline \multicolumn{4}{|l|}{$\begin{array}{l}\text { Treatments (used by } \geq 20 \% \text { patients in } \\
\text { any group) }\end{array}$} \\
\hline Short-acting beta-agonists & $69.8 \%$ & $45.1 \%$ & $61.6 \%$ \\
\hline LABA & $8.9 \%$ & $16.5 \%$ & $20.2 \%$ \\
\hline Long-acting muscarinic-antagonist & $2.2 \%$ & $71.6 \%$ & $50.7 \%$ \\
\hline ICS & $53.5 \%$ & $16.5 \%$ & $27.6 \%$ \\
\hline Fixed ICS/LABA combinations & $34.9 \%$ & $57.5 \%$ & $68.3 \%$ \\
\hline Antibiotics & $13.8 \%$ & $33.3 \%$ & $37.0 \%$ \\
\hline Oral steroids & $20.9 \%$ & $32.4 \%$ & $43.1 \%$ \\
\hline \multicolumn{4}{|l|}{$\begin{array}{l}\text { Comorbidities that can affect inhaler } \\
\text { handling (observed in } \geq 10 \% \text { patients in } \\
\text { any group) }\end{array}$} \\
\hline Any & $15.8 \%$ & $50.4 \%$ & $55.3 \%$ \\
\hline Heart failure & $2.0 \%$ & $21.8 \%$ & $22.9 \%$ \\
\hline Stroke & $1.6 \%$ & $10.8 \%$ & $9.7 \%$ \\
\hline Sleep disorders & $3.8 \%$ & $7.2 \%$ & $10.5 \%$ \\
\hline Depression or anxiety & $8.1 \%$ & $14.4 \%$ & $17.7 \%$ \\
\hline Osteoporosis & $1.2 \%$ & $7.7 \%$ & $10.2 \%$ \\
\hline
\end{tabular}

COPD, chronic obstructive pulmonary disease; ICS, inhaled corticosteroids; LABA, long-acting beta-agonists; SD, standard deviation.

\section{P141 2-YEAR FOLLOW-UP OF COPD PATIENTS IN THE NON- INTERVENTIONAL 'REAL-LIFE' DACCORD STUDY IN GERMANY}

${ }^{1} \mathrm{H}$ Worth, ${ }^{2} \mathrm{R}$ Buhl, ${ }^{3} \mathrm{CP}$ Criée, ${ }^{4} \mathrm{P}$ Kardos, ${ }^{5} \mathrm{C}$ Mailänder, ${ }^{5} \mathrm{~N}$ Lossi, ${ }^{6} \mathrm{C}$ Vogelmeier. ${ }^{1}$ Facharztforum Fürth, Fürth, Germany; ${ }^{2}$ Pulmonary Department, Mainz University Hospital, Mainz, Germany; ${ }^{3}$ Department of Sleep and Respiratory Medicine, Evangelical Hospital Goettingen-Weende, Bovenden, Germany; ${ }^{4}$ Group Practice and Centre for Allergy, Respiratory and Sleep Medicine, Red Cross Maingau Hospital, Frankfurt, Germany; ${ }^{5}$ Novartis Pharma GmbH, Nürnberg, Germany; ${ }^{6}$ Department of Medicine, Pulmonary and Critical Care Medicine, University Medical Centre Giessen and Marburg, Philipps-University Marburg, Member of the German Centre for Lung Research (DZL), Marburg, Germany

\subsection{6/thoraxjnl-2016-209333.284}

Introduction Although randomised, controlled trials are important in the development of new pharmacological treatments, they provide limited information on the 'real life' management of chronic diseases. Here, we analysed two-year follow-up data from the prospective, non-interventional, observational DACCORD study to evaluate the frequency of exacerbations and the evolution of disease severity using GOLD 2011 categorization.

Methods COPD out-patients were recruited into DACCORD following either a change or initiation of COPD maintenance medication and followed up for 2 years. Data of 3137 patients that completed the 2-year follow-up were analysed; Exacerbation data were collected from the 6 months prior to study entry (baseline), and every 3 months for 2 years after entry; COPD symptoms were evaluated using the COPD Assessment Test (CAT) at baseline as well as the 1 year and 2 year visit.
Results In this cohort the non-exacerbating phenotype was stable with a total of $69.4 \%$ of patients without exacerbations in the 6 months prior to baseline not reporting any exacerbation over the full 2 year follow-up period resulting in an annual exacerbation rate of 0.263 in year 1 and 0.251 in year 2 . In contrast, patients with at least one exacerbations in the 6 months prior to baseline showed an annual exacerbation rate of 0.770 in year 1 and 0.633 in year 2. At baseline $44.6 \%$ of patients were categorised as GOLD D, one third of these due to their exacerbation history alone. In Year 1 there was a general shift to lower risk categories compared to baseline (GOLD D: $44.6 \%$ vs. $31.1 \%$ ) mainly due to a lower number of exacerbations in Year 1. Overall, categorization then remained relatively stable from Year 1 (GOLD $\mathrm{D}=31.1 \%)$ to Year 2 (GOLD D $=32.1 \%)$.

Conclusions Although, COPD is generally considered to be a progressive disease, this analysis of 'real life' data over an observational period of 2 years shows that the 'non-"exacerbating' phenotype is relatively stable. The data furthermore confirms that exacerbations in the recent history increase the risk of future exacerbations.

\section{P142 THE DISTRIBUTION OF BLOOD EOSINOPHIL COUNT IN A COPD CLINICAL TRIALS DATABASE: COMPARING THE UK WITH THE REST OF THE WORLD}

${ }^{1}$ E Hilton, ${ }^{1} \mathrm{C}$ Compton, ${ }^{1} \mathrm{D}$ Midwinter, ${ }^{1,2} \mathrm{~N}$ Barnes. ${ }^{1}$ GlaxoSmithKline, Brentford, UK; ${ }^{2}$ William Harvey Institute Barts and the London School of Medicine, UK

\subsection{6/thoraxjnl-2016-209333.285}

Introduction There is accumulating evidence that blood eosinophil count may have predictive value for those individuals with COPD who are more likely to respond to an inhaled corticosteroid in terms of exacerbation reduction and there is evidence that higher blood eosinophil count can also have some predictive value for those at risk of exacerbations. Blood eosinophil counts are known to be raised in a number of conditions including allergies and parasitic or fungal infections. It is therefore possible that the blood eosinophil count would vary between countries and thus influence their predictive value. We have investigated the distribution of blood eosinophil counts in the UK in comparison with blood eosinophil counts worldwide from data in the GSK clinical trials database.

Methods In this post-hoc analysis, the following criteria were used to select studies for consistency with analyses conducted to examine the effects of inhaled corticosteroids on outcomes: global, randomised, double-blind, parallel-group clinical trials in COPD of at least 24 weeks' duration that included any of fluticasone propionate (FP), fluticasone furoate (FF), salmeterol/FP or $\mathrm{FF} /$ vilanterol (VI) as a randomised study drug and a non-steroidcontaining arm and for which subjects had a pre-randomisation blood sample taken for eosinophils. ${ }^{1,2}$ Individual subjects' prerandomisation eosinophil counts from countries that recruited at least 100 subjects across all trials were pooled to form the global sample (Argentina, Australia, Canada, Chile, Czech Republic, Denmark, Estonia, France, Germany, Greece, Italy, Korea, Lithuania, Mexico, Netherlands, Norway, Peru, Philippines, Poland, Romania, Russia, Slovakia, South Africa, Spain, Sweden, United Kingdom, United States). Individual subjects' pre-randomisation eosinophil counts for subjects in the UK were pooled to form the UK sample. An empirical cumulative distribution function (CDF) for the UK sample was overlaid on an empirical CDF plot for the global sample. 